\title{
CORRECTIONS
}

\section{Facing up to the prescription opioid crisis}

As a result of an editorial misunderstanding, figure 2 of this article by Irfan A Dhalla and colleagues (BMJ 2011;343:d5142, doi:10.1136/bmj.d5142) overestimates the number of deaths in Victoria involving oxycodone. Additionally, the data for the figure were provided by Angela Rintoul (and not taken from reference 5, as we had stated). We have now posted the correct figure online (www.bmj.com/content/343/bmj.d5142/suppl/ DC1).

Cite this as: BMJ 2011;343:d5729

๑ BMJ Publishing Group Ltd 2011 